\title{
O COMPREENDER COM A ATD EM UMA ETNOPESQUISA-FORMAÇÃO COM PROFESSORES DE CIÊNCIAS
}

\author{
UNDERSTANDING ETHNORESEARCH IN SCIENCE TEACHER \\ EDUCATION BY USING THE DTA
}

\author{
Charles Guidotti ${ }^{1}$ \\ Valmir Heckler ${ }^{2}$
}

\begin{abstract}
Resumo: O artigo apresenta questões epistemológicas e filosóficas, e a exemplificação teórico-prática da busca por compreender com a Análise Textual Discursiva (ATD) em uma etnopesquisa-formação com professores de Ciências. Abrange aspectos de se desenvolver pesquisa qualitativa em uma abordagem fenonomenológica hermenêutica em que o compreender acontece aos pesquisadores pela e com a linguagem por meio de descrição e interpretação. O descrever e o interpretar são apresentados associados à experiência vivida dos pesquisadores no constituir das informações em análise no estudo e nos modos de ampliar, aperfeiçoar e comunicar ideias com a ATD a partir de um fenômeno situado. Mostra-se o processo analítico de unitarização e categorização, e o mergulho hermenêutico com movimentos de colocar em suspensão as perguntas iniciais da pesquisa e de constituir a auto-organização da escrita recursiva dos metatextos. Emergem, a partir das informações individuais e coletivas, a estruturação e a validação dos argumentos no comunicar o que se compreendeu no processo formativo investigado.
\end{abstract}

Palavras-chave: Análise Textual Discursiva; Etnopesquisa-Formação; Pesquisa Qualitativa; Fenomenologia Hermenêutica; Metatexto.

\begin{abstract}
This paper introduces epistemological and philosophical issues, besides a theoretical-practical example, of the search that aims at understanding Ethnoresearch in Science Teacher Education by using the Discursive Textual Analysis (DTA). It covers aspects involved in the development of qualitative research in a hermeneutical-phenomenological approach in which researchers' understanding happens through the use of language and with it, when description and interpretation are carried out. Describing and interpreting are associated with researchers' experiences when they transform information under analysis into the study and into ways of expanding, improving and communicating ideas by the DTA. Analytical processes of unitarization and categorization, besides the hermeneutical dive, are shown as movements to set aside early research questions and to carry out self-organization of recursive writing of metatexts. From individual and collective information, structuring and validation of arguments emerge in the communication of what was understood in the education process under investigation.
\end{abstract}

Keywords: Discursive Textual Analysis; Ethnoresearch Formation; Qualitative Research; Hermeneutic Phenomenology; Metatext.

\footnotetext{
${ }^{1}$ Doutor em Educação em Ciências pela Universidade Federal do Rio Grande (FURG). Professor adjunto no Instituto de Matemática, Estatística e Física da FURG, campus Santo Antônio da Patrulha, Santo Antônio da Patrulha, Rio Grande do Sul, Brasil. Integrante do grupo de pesquisa Comunidade de Indagação em Ensino de Física Interdisciplinar (CIEFI). E-mail: charles.guidotti@ furg.br

${ }^{2}$ Doutor em Educação em Ciências pela Universidade Federal do Rio Grande (FURG). Professor adjunto no Instituto de Matemática, Estatística e Física da FURG, campus Rio Grande, Rio Grande, Rio Grande do Sul, Brasil. Líder do grupo de pesquisa Comunidade de Indagação em Ensino de Física Interdisciplinar (CIEFI). E-mail: valmirheckler@ furg.br
} 


\section{Introdução}

No presente texto, apresentamos questões epistemológicas, filosóficas e práticas da construção e comunicação da busca por compreender com a Análise Textual Discursiva (ATD) em uma etnopesquisa-formação em abordagem fenomenológica hermenêutica. A escrita desenvolve-se em torno da indagação: o que se mostra da compreensão ao se transformarem em conhecimento produções escritas de professores de Ciências participantes de um processo formativo em comunidade?

As ideias comunicadas neste artigo ampliam o estudo desenvolvido por Guidotti $(2019)^{3}$, apoiando-se nele em termos de exemplificação. O autor buscou compreender a investigação na formação acadêmico-profissional com professores de Ciências participantes do projeto de extensão intitulado CIRANDAR: Rodas de investigação desde a escola. O referido estudo, situado no campo da formação de professores, desenrolou-se a partir de 43 relatos produzidos por professores da área da Ciências da Natureza em formação no projeto nas edições de 2016 e 2017. O CIRANDAR constitui-se em um espaçotempo $^{4}$ de formação acadêmico-profissional de professores da universidade e da escola, bem como de licenciandos. Nesse espaçotempo, que tem duração de aproximadamente oito meses, os professores em formação buscam significar experiências vividas em sala de aula por meio do registro, da teorização, da leitura do outro e da partilha. Para isso, no CIRANDAR, a escrita assume função epistêmica, em um processo recursivo do participante na busca de expressar compreensões de seu objeto em estudo. Esse objeto é um produto do pensamento, que, por sua vez, oportuniza aos professores (re)construírem um marco teórico que permite planejar, planificar, produzir e projetar propostas educativas, levando em conta as complexas características envolvidas na realidade profissional.

Apoiados nos pressupostos da etnopesquisa em uma abordagem fenomenológica, analisamos as maneiras pelas quais os professores participantes do CIRANDAR desenvolvem investigação na e sobre a sua sala de aula de Ciências. A contar da indagação inicial, é fundante investigarmos as relações entre o conhecimento teórico-

\footnotetext{
${ }^{3} \mathrm{O}$ segundo autor do texto foi o orientador da tese de doutoramento do primeiro autor, assumindo-se nesta escrita como etnopesquisador por estar envolvido no estudo e ser participante da comunidade formativa em análise.

${ }^{4}$ O termo é empregado para registrar a simultaneidade entre investigação e formação, superando a dicotomização entre a prática/teoria e teoria/prática, entre o pensar/fazer e o fazer/pensar.
} 
prático da comunidade de professores de Ciências em formação no projeto e os conhecimentos construídos pelos pesquisadores a partir desses conhecimentos.

Em vista do referido contexto, encaminhamos a descrição e a interpretação do percurso metodológico assumido na busca por compreender com a ATD. Seguimos a perspectiva fenomenológica de chegar à compreensão dos fenômenos; assim, a indagação inicial foi ampliada em três outras: como procedemos de forma fenomenológica hermenêutica na busca por compreender com o campo empírico? De que forma ampliamos compreensões com este campo empírico? De que maneiras estruturamos, a partir da Análise Textual Discursiva, a comunicação das compreensões?

Apesar das indagações propostas, não ousamos, nesta escrita, fornecer ao leitor uma sequência de passos, como um procedimento canônico. A intenção é apresentar caminhos possíveis a serem trilhados na análise de informações oriundas de textos produzidos por professores que expressam aspectos teórico-práticos de experiências vividas, orientados por pressupostos fenomenológicos com a Análise Textual Discursiva. De modo geral, os referidos caminhos, concordando com as ideias de Moraes (2019), não são lineares, nem contínuos, tampouco conferem a certeza de conduzir a um objetivo predeterminado.

Com a pretensão de expressarmos compreensões atuais e reconstruídas sobre o processo a partir do qual entendemos que se realize a ampliação de como se buscou compreender e comunicar com a Análise Textual Discursiva (ATD) em uma etnopesquisa-formação, organizamos o artigo em quatro seções: $O$ compreender na etnopesquisa-formação fenomenológica; Situar o fenômeno e encaminhar a análise; Análise Textual Discursiva como mergulho hermenêutico no fenômeno situado; Considerações finais: argumentos que comunicam compreensões.

\section{0 compreender na etnopesquisa-formação fenomenológica}

É importante expor o que assumimos por compreender, uma vez que essa palavra aparece intensamente em nosso texto. Faremos isso pautados na forma de desenvolver pesquisa qualitativa em uma abordagem fenomenológica hermenêutica e de comunicar como perpassam os nossos modos de constituir as informações e encaminhamentos de análise.

Assumimos que o compreender acontece aos pesquisadores pela e com a linguagem, como é apresentado por Gadamer (1999). A partir do referido autor, 
assumimos que, ao desenvolvermos pesquisa no viés hermenêutico, buscamos compreender. Isso abrange desenvolver acordos, entendimentos, e constituir com diferentes interlocutores o próprio objeto aperfeiçoável em análise. O objeto assumido no texto é o que Gadamer descreve como "a coisa". Importante ressaltar que, “[...] na experiência hermenêutica, encontra-se algo como uma dialética, um fazer da própria coisa, um fazer que, à diferença da metodologia da ciência moderna, é um padecer, um compreender, que é um acontecer" (GADAMER, 1999, p. 674). Nesse fazer assumido pelo autor, a linguagem é o meio de se constituírem compreensões, com diferentes interlocutores, como uma negociação que se dá interligada ao contexto da experiência vivida.

Durante o processo de busca por compreender, é fundamental assumir postura de deixar emergir respostas provisórias. Segundo Gadamer (1999), o que será constituído em uma conversação, ninguém pode saber por antecipação. Trata-se de um processo lento a ser constituído, e nisso "[...] a linguagem é o médium universal em que se realiza a própria compreensão. A forma de realização da compreensão é a interpretação" (GADAMER, 1999, p. 566). É a forma de buscar conhecer o que um determinado fenômeno significa e como ele é experienciado (BICUDO, 2011). Comprendemos esse ser também movimento no constituir a etnopesquisa-formação com professores dentro da perspectiva da fenomenologia hermenêutica.

A investigação hermenêutica solicita um trabalho interpretativo. O compreender é expresso via produção textual na pesquisa qualitativa, interligado a aspectos estruturais do descrever e interpretar a experiência vivida dos pesquisadores no constituir as informações em análise no estudo. Destaca-se como um movimento de ampliar e aperfeiçoar ideias a partir de um possível fenômeno situado, dentro do campo de estudo.

Segundo Bicudo (2011), na fenomenologia hermenêutica, a descrição da experiência vivida, em que se revelam as vivências, é importante, mas não suficiente. Nisso, a autora destaca que se solicita um trabalho interpretativo hermenêutico, visando a compreender sentido, significado apontado na descrição. Importante significar que a investigação hermenêutica se diferencia da Análise de Conteúdo e que não busca explicar ocorrência a partir de teorias e pressupostos já conhecidos (BICUDO, 2011).

As respostas não se revelam diretamente no narrar a experiência e nas "[...] descrições não se mostram de imediato, de modo direto, mas vão se revelando mediante a compreensão do sentido das experiências vividas pelo sujeito, olhadas na sua totalidade" (BICUDO, 2011, p. 56). Nisso, coloca-se o desafio aos pesquisadores, em que diferentes 
informações em análise precisam ser significadas, interligadas a "lembranças", aos seus movimentos formativos, ao que lhes acontece em grupos de pesquisa, com interlocuções teóricas e com os registros constituídos ao longo do processo de investigação.

No ampliar compreensões, via escrita, a linguagem mostra-se como um dos artefatos básicos desenvolvidos pela humanidade com função epistêmica (MARQUES, 2011). Nisso, também se colocam a escrita e a leitura recursiva no organizar, desenvolver e comunicar pensamentos sobre o objeto em constituição. Um cenário que implica simultaneamente transformações dos pesquisadores, desafiando-os a assumirem pressupostos de natureza epistemológica, ontológica e metodológica. A forma de constituir as informações do estudo e sua análise abrange a busca por superar os modelos de ciência deterministas e, com isso, valorizar os sujeitos envolvidos na análise e os pesquisadores como autores das compreensões emergentes no estudo (MORAES; GALIAZZI, 2016).

O movimento hermenêutico assumido é o da "busca por compreender" a partir da investigação de um objeto aperfeiçoável. Abrange movimento de escrita intensa, que se amplifica, em forma de espiral, ao se trabalhar na análise com informações, experiências e conhecimentos constituídos em diferentes comunidades (WELLS, 2016), conforme ilustrado na Figura 1. 
Figura 1: O papel de um objeto aperfeiçoável na construção do conhecimento

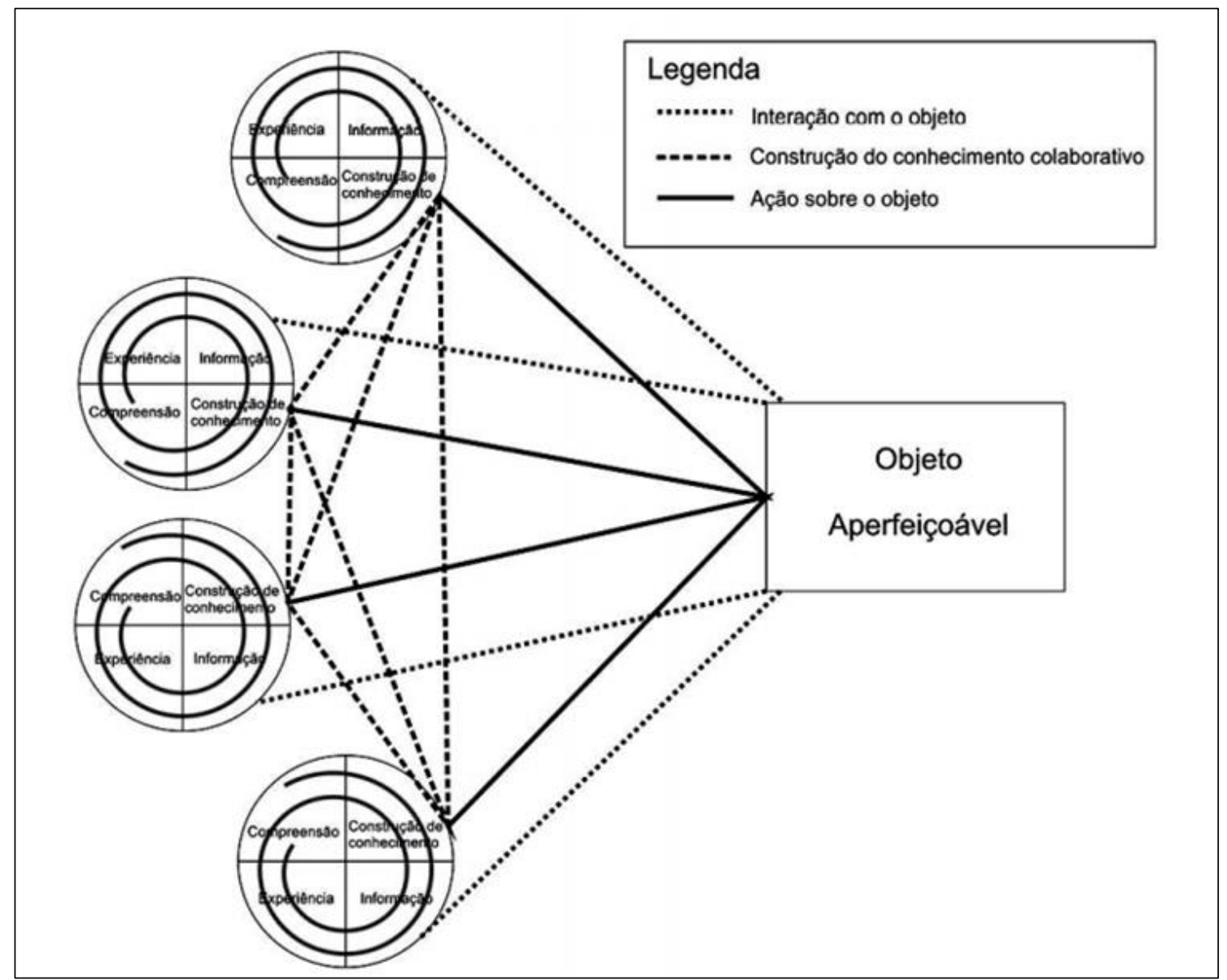

Fonte: Adaptado de Wells (2016, p. 71)

A partir da Figura 1, expressa-se o modo como constituímos a interação, a construção do conhecimento e a ação sobre o objeto aperfeiçoável. Isso abrange diferentes movimentos de interagir com colegas, interlocutores teóricos e pessoas da comunidade frente às distintas ações necessárias no construir conhecimento. Reconhecemos ser a escrita forma sistematizada de comunicar o que se compreendeu no referido processo investigativo, pois, ao escrever, nos ocorrem

[...] insights, abstrações, comparações, articulações, reunindo e separando aspectos, expressando o compreendido pela linguagem, quando obtemos clareza e ficamos em dúvida, enfim são movimentos do pensar ao percorrer os meandros do pensamento investigativo (...) (BICUDO, 2011, p. 59).

Coloca-se aí o desafio de incluir, na escrita, os encontros com leituras e falas de diferentes interlocutores, teóricos, colegas de trabalho, estudantes, grupos de pesquisa, no desenvolver uma boa conversa, com os mais e menos experientes, sobre a(s) temática(s) em estudo.

Os pesquisadores, no contexto da etnopesquisa, consideram o mundo como um objeto de percepções e ações do senso comum (COULON, 2017). O que exemplificamos 
no estudo é como constituímos um caminho metodológico a partir da imersão nas práticas de uma comunidade de professores. Um ponto a ser considerado é que os pesquisadores necessariamente estão imersos na comunidade em que investigam. Passamos a evidenciar as formas como procedemos na constituição das informações no estudo desenvolvido em Guidotti (2019): A investigação desde a sala de aula de ciências: processo de autoformação com aperfeiçoamento teórico-prático de professores no CIRANDAR.

O caminho metodológico da referida pesquisa foi construído a partir das experiências vividas e relatadas por meio da escrita de professores em formação no projeto de extensão acadêmico-profissional intitulado CIRANDAR: Rodas de Investigação desde a escola. Os relatos produzidos, durante seis edições do curso, são fixadores de experiências, como registro objetivo do vivido (MACEDO, 2010), no qual se expressam discursos sobre as vivências da/na sala de aula. Desse modo, a busca por compreensões do que se mostra da investigação, nesse processo formativo de professores, foi assumida na perspectiva da interpretação hermenêutica (BICUDO, 2011).

O referido caminho metodológico diferencia-se da ideia da coleta de dados ao se trabalhar com um objeto aperfeiçoável constituído com informações. Aproximamos esse objeto da "coisa" a ser compreendida. Importante ressaltar que esse dado, na fenomenologia hermenêutica, é o "[...] que chega ao sujeito que, de modo atento, olha para algo querendo saber do que se trata. Esse algo poderia ser visto como a 'coisa', que nos escapa ao conhecimento, mas que se doa aos nossos sentidos, em seus modos de doação" (BICUDO, 2020, p. 34). Na abordagem fenomenológica, o que se mostra aos pesquisadores é um fenômeno situado na experiência vivida no conjunto de informações constituído de forma colaborativa.

Assim, aproximamos a etnopesquisa-formação da perspectiva de fazer investigação hermenêutica. Assumimos esse modo de fazer investigação, com base em Macedo (2010), como uma linha não linear e multirreferencial, partindo de ações cotidianas dos atores sociais. A seguir, evidencia-se o caminho no situar o fenômeno e no analisar a linguagem construída com professores em formação que questionam e investigam a sua prática profissional.

\section{Situar o fenômeno e encaminhar a análise}

No contexto do estudo de Guidotti (2019), a busca por situar o fenômeno e constituir o processo de análise aconteceu em torno da interrogação fenomenológica: o 
que é isso que se mostra da investigação nos relatos dos professores de Ciências em formação no CIRANDAR? A referida interrogação, em uma perspectiva filosófica da fenomenologia hermenêutica, orientou inicialmente o percurso da etnopesquisa, na busca por compreender o que se mostrava da investigação na formação acadêmico-profissional de professores de Ciências.

No entanto, na perspectiva fenomenológica, o fenômeno não está posto previamente, exigindo o mergulho dos pesquisadores na região do campo investigado, uma vez que os conhecimentos guiados pela interrogação inicial são construídos nesse solo. Com isso, a primeira tarefa foi descrever o CIRANDAR, no sentido de buscar compreender aspectos históricos, epistemológicos e práticos que constituem o referido projeto de extensão. O movimento descritivo aconteceu mediante a leitura dos registros das primeiras seis edições do projeto, em que os pesquisadores desenvolveram comparações e articulações, bem como reuniram e separaram aspectos e informações que se mostraram importantes para a investigação desenvolvida.

Esse primeiro movimento descritivo, além de possibilitar compreender o CIRANDAR, oportunizou que os pesquisadores encontrassem experiências vividas por professores, apresentadas na forma de relatos, concernentes à interrogação inicial. De acordo com Bicudo (2011), trata-se de um movimento que enlaça também a procura por sujeitos significativos que possam dizer de experiências, vividas em seu cotidiano, que se mostrem consonantes com os objetivos estabelecidos na pesquisa.

A partir da descrição e compreensão da constituição do campo em que a investigação se desenrola, os pesquisadores lançaram-se no movimento de focar em relatos desenvolvidos por professores de Ciências da Natureza, comunicados nas edições de 2016 e 2017 do CIRANDAR. O referido recorte do campo empírico justificou-se pela formação dos pesquisadores e por sua inserção no percurso formativo do CIRANDAR, que acontece a partir do ano de 2016. Desse modo, constituíram o corpus de análise relatos produzidos por professores em formação ligados às áreas do conhecimento da Física, Química, Biologia e Ciências, chegando-se ao quantitativo de 43 relatos de experiências, que foram descritos com o objetivo de encontrar o fenômeno.

Na perspectiva de deixar um fenômeno manifestar-se à consciência - a contar da interrogação "o que é isso que se mostra da investigação nos relatos dos professores de Ciências em formação no CIRANDAR?" -, descrevemos as produções colocando em evidência sentidos que fossem importantes, tendo como norte a interrogação formulada. Os aspectos em destaque ao longo da descrição são exemplos de unidades de sentido que 
auxiliaram, em um primeiro momento, a situar e, posteriormente, a compreender o fenômeno. No Quadro 1, exemplificamos esse movimento descritivo.

Quadro 1: Exemplo do movimento de descrição dos relatos.

No âmbito do estágio supervisionado da licenciatura em Química da UNIPAMPA, encontram-se os trabalhos de Machado- R12 e Santos- R26. Machado- R12, além de descrever atividades de ensino desenvolvidas, discorreu sobre as potencialidades da contextualização no ato de ensinar Química. Desse modo, Machado- R12 anuncia a compreensão de que a contextualização oportuniza "provocar os estudantes a pesquisar e debater entre si as questões que são abordadas a partir de um contexto social, ético, entre outros meios" e de que o "[...] ensino se torna mais dinâmico e prazeroso, no qual o estudante, aguçado pela prática da leitura, busque a resolução de problemas como forma de aprimorar seus conhecimentos".

Fonte: Guidotti (2019, p. 140)

As descrições desenvolvidas revelam experiências vividas pelos professores de Ciências que foram utilizadas no constituir a análise no estudo. A contar desse movimento descritivo, o que se mostrou à consciência dos pesquisadores refere-se à valorização das práticas de sala de aula no constituir significados profissionais. Nessa perspectiva, a investigação sobre a/na sala de aula dos professores mostrou-se como espaçotempo de formação acadêmico-profissional, com aperfeiçoamentos teórico-práticos.

A partir da emergência do que se mostrou sobre a investigação desde a sala de aula na formação de professores, aperfeiçoamos a interrogação de pesquisa para: o que é isso da investigação dos professores sobre a/na sala de aula de Ciências? Assim sendo, a interrogação colocou em suspensão o fenômeno situado - a investigação sobre a/na sala de aula de Ciências, e com isso partimos para a (re)leitura dos relatos, com o objetivo de encontrar, além daquelas já evidenciadas, novas unidades de sentido. Na seção seguinte, explicitaremos o caminho analítico, guiados pelos princípios da Análise Textual Discursiva (ATD), dos relatos dos professores de Ciências participantes do CIRANDAR nas edições 2016 e 2017.

\section{Análise Textual Discursiva como mergulho hermenêutico no fenômeno situado}

A Análise Textual Discursiva possibilitou o mergulho no corpus de pesquisa, em um movimento interpretativo de natureza qualitativa com caráter hermenêutico, pela escrita articulada de interlocuções teóricas e empíricas emergentes da linguagem da investigação sobre a/na sala de aula de Ciências. Foi forma de os pesquisadores constituírem o compreender a investigação na formação acadêmico-profissional de professores de Ciências participantes do CIRANDAR: Rodas de investigação desde a escola. 
Seguindo esses indicativos metodológicos, salientamos que a etnopesquisa não se trata de uma metodologia ou método de pesquisa, mas sim de uma perspectiva voltada para o interesse da compreensão de ordem social (BARBOSA; BARBOSA, 2008). Desse modo, ao assumirmos a etnopesquisa-formação em uma abordagem fenomenológica como construção do percurso investigativo, nossa intencionalidade esteve direcionada à busca por compreender como a investigação é explicitada, dentro de uma abordagem sociocultural, por professores em formação no projeto CIRANDAR. A questão é investigar como os atores sociais (sujeitos da pesquisa) produzem os seus mundos, quais regras que ordenam esses mundos e seus julgamentos (COULON, 2017).

Nesse sentido, a análise buscou expressar compreensões, em forma de texto, pela ATD, em um processo auto-organizado, ao realizar a análise da linguagem expressa pelo coletivo, em forma de relatos, que constituíram o conjunto de informações a serem sistematizadas e organizadas. No compreender o fenômeno associado à experiência vivida, os pesquisadores assumem que, pela análise textual discursiva, foram possibilitados aperfeiçoamentos teórico-práticos das atividades propostas à comunidade de professores. Assim, o processo de análise também se constituiu em movimento de transformações dos pesquisadores.

$\mathrm{Na}$ análise, as linguagens registradas nos relatos em estudo, bem como as interlocuções com teóricos e as interpretações dos pesquisadores, foram assumidas como emergentes do campo empírico. Para serem analisadas pela ATD, independentemente de suas origens, as informações são transformadas em documentos escritos para, então, serem submetidas à análise. $\mathrm{Na}$ análise, são organizadas pela produção de unidades de significado escritas e codificadas, a fim de estruturar a investigação, e constituem-se em espaçotempo da ampliação de pensamentos.

Logo, as compreensões construídas pelos pesquisadores ao longo da investigação não foram resultado apenas da interpretação de textos produzidos por professores em formação, mas resultado de um processo de entendimento, experienciado pelos pesquisadores, em que a escrita assume uma função central na construção do conhecimento. Nessa auto-organização das informações, a ATD possibilita compreender alguns pressupostos, como "[...] o reconhecimento do outro, os movimentos circular e espiral, que auxiliam no caminho de análise, e a abertura à ampliação de horizontes interpretativos pela busca de teorias emergentes na análise" (SOUSA; GALIAZZI, 2016, p. 33). A pesquisa fenomenológica vale-se essencialmente das manifestações orais e 
escritas dos sujeitos, e na análise das referidas manifestações é constituído o compreender dos fenômenos investigados.

Desenvolver ATD leva tempo; é um processo recursivo que envolve a (trans)formação dos pesquisadores. Segundo Moraes e Galiazzi (2016), é um processo de análise, via escrita, com movimento constante de construção e reconstrução a partir de descrição e interpretação, possibilitando a modificação dos conhecimentos e teorias dos sujeitos que pesquisam, de seus entendimentos e paradigmas de ciência e dos próprios pesquisadores e de suas realidades.

Após situar o fenômeno, o voltar ao campo empírico, ou seja, a (re)leitura dos relatos inúmeras vezes, significou buscar sentidos do dito em relação à nova interrogação, olhando para o que os professores de Ciências estavam expressando acerca do fenômeno que se mostrou aos pesquisadores na descrição - investigação sobre a/na sala de aula de Ciências. Nesse procedimento, foram destacadas unidades de sentido que se revelaram como aspectos empíricos emergentes da análise dos textos, o que é assumido como processo de unitarização (MORAES; GALIAZZI, 2016). Na pesquisa que descrevemos e utilizamos como exemplo ao longo deste texto, obtivemos 250 unidades de sentido, em um movimento de atribuir códigos, desenvolver unidade de sentido e interpretar via títulos, conforme expresso no Quadro 2.

Quadro 2: Recorte das unidades de sentido e as suas codificações

\begin{tabular}{|c|l|c|c|}
\hline Código & \multicolumn{1}{|c|}{ Unidade de sentido } & Título & $\begin{array}{c}\text { Categoria } \\
\text { inicial }\end{array}$ \\
\hline R8.1 & $\begin{array}{l}\text { A relação com o estágio me acompanha } \\
\text { desde minha formação inicial, não apenas } \\
\text { por ser exigência para receber o título de } \\
\text { "professora", mas por proporcionar } \\
\text { diversas experiências, como a de ser muito } \\
\text { bem acolhida pela professora regente da } \\
\text { turma em que realizei o estágio, assim } \\
\text { como pelos demais professores da escola. }\end{array}$ & $\begin{array}{c}\text { A investigação do professor a } \\
\text { partir das suas experiências de } \\
\text { sala de aula }\end{array}$ & 16 \\
\hline R10.1 & $\begin{array}{l}\text { [...] ao recordar das nossas aulas, lembro } \\
\text { que fazíamos de cada aula um lugar de } \\
\text { escuta e de discussão, em que a } \\
\text { participação de cada um fazia "a } \\
\text { diferença", pois a partir dela poderiam } \\
\text { surgir temas para discutirmos nas aulas. } \\
\text { Além disso, em cada encontro, um dos } \\
\text { alunos apresentava alguns aspectos dos } \\
\text { textos a respeito de experimentação, de } \\
\text { legislação, e, a partir daí, discutíamos no } \\
\text { grupo. Dessa forma, cada um tornava-se } \\
\text { corresponsável pela aula. }\end{array}$ & corresponsável pela aula \\
\hline
\end{tabular}




\begin{tabular}{|l|l|l|l|}
\hline A investigação do professor nos mostra que & & \\
R9.9.CH & $\begin{array}{l}\text { os professores da escola buscam } \\
\text { informações para as suas formações em }\end{array}$ & $\begin{array}{c}\text { A formação de professores na } \\
\text { escola acontece em eventos com }\end{array}$ & 11 \\
eventos a serem realizados na própria & autores externos, com registros e & 11 \\
escola, com palestras e espaços de & compartilhamento de \\
compartilhamento de experiências narradas & experiências de sala de aula & \\
em portfólios.
\end{tabular}

Fonte: Guidotti (2019, p. 162)

No quadro, exemplificamos três unidades de sentido, atribuindo código para cada unidade, com letras e números. O sistema de códigos indica aos pesquisadores o relato que originou a unidade e a localização dentro do relato. Desse modo, o código R8.1 identifica uma unidade que foi extraída do relato 8 , sendo a primeira unidade de sentido dessa escrita. Além disso, o processo de análise pela ATD possibilitou aos pesquisadores que criassem as suas próprias unidades de sentido. Para identificar as referidas unidades, utilizamos uma letra, tal como R9.9.CH. Esse código significa que esta unidade não está localizada diretamente no texto, porém expressa sentidos implícitos nas proximidades da unidade R9.9.

A terceira coluna do Quadro 2 apresenta os títulos atribuídos a cada unidade de sentido. Os títulos reúnem sentidos das unidades colocadas em evidência na primeira coluna, além de transformarem expressões da linguagem cotidiana do sujeito em uma linguagem condizente com aquela do campo de inquérito dos pesquisadores (BICUDO, 2011). Desse modo, a construção de compreensões em torno do corpus de análise envolveu um movimento recursivo intenso de escrita e leitura na busca de complexificar a argumentação em torno das questões norteadoras e dos propósitos da pesquisa. Utilizamos a planilha eletrônica em função da possibilidade de codificação, organização, comparação e modificação, o que potencializou a construção recursiva da escrita nesse conjunto de informações disponíveis.

A partir da confluência das unidades de sentido, emergiram as categorias iniciais. De acordo com Moraes e Galiazzi (2016), o movimento de categorização é um processo de criação, ordenamento, organização e síntese. Assim, a categorização aconteceu a contar da comparação dos títulos atribuídos a cada unidade de sentido, levando à articulação das ideias abrangentes, que expressam a generalidade do fenômeno (BICUDO, 2011) - a investigação sobre a/na sala de aula de Ciências.

O movimento de categorização foi longo e lento, desafiando os pesquisadores a retornarem constantemente à leitura dos relatos, uma vez que foi nesse movimento que se deu o processo da sistematização das compreensões do fenômeno em estudo. Nesse 
processo, além de reunirem-se elementos semelhantes, também se nomeiam e se definem categorias, cada vez com maior precisão (MORAES; GALIAZZI, 2016), eliminando-se os excessos de informações. As categorias iniciais foram sendo delimitadas e aperfeiçoadas, constituindo um novo nível de categorização: o das categorias intermediárias.

No Quadro 3, apresentamos as categorias intermediárias, que constituem o segundo nível de categorização construído no estudo.

Quadro 3: Categorias intermediárias pela organização das categorias iniciais

\begin{tabular}{|c|c|c|}
\hline $\begin{array}{c}\text { Código das } \\
\text { categorias iniciais }\end{array}$ & $\begin{array}{c}\text { Categoria intermediária } \\
\text { Registros de ações de sala de aula }\end{array}$ & $\begin{array}{c}\text { Código da } \\
\text { categoria final }\end{array}$ \\
\hline 8,13 & A experiência de sala de aula oportuniza o aperfeiçoamento & A \\
\hline 16,20 & profissional a partir do diálogo desde a sala de aula & A investigação narrativa \\
\hline 19 & A prática reflexiva em coletivos de professores & B \\
\hline $10,11,15,31$ & Parceria entre escola e universidade & B \\
\hline 9,12 & A formação de professores e as políticas públicas & B \\
\hline 22,24 & Pesquisa-ação colaborativa & B \\
\hline 2 & Saberes teórico-práticos do professor & C \\
\hline 1,5 & Planejamento coletivo & C \\
\hline 17,18 & O diálogo na reestruturação curricular & C \\
\hline 23 & O aperfeiçoamento da prática pedagógica & C \\
\hline 6,21 & A leitura e a fala dos estudantes nas aulas de Ciências & D \\
\hline $27,28,3$ & A linguagem no constituir e negociar significados & D \\
\hline 26,29 & A investigação como estratégia de ensino em sala de aula & D \\
\hline
\end{tabular}
Fonte: Guidotti (2019, p. 164)

Cada categoria corresponde a um conjunto de unidades de significados que expressam ideias semelhantes. Durante todo o processo de análise, a ATD desafia os pesquisadores a construírem sínteses dos significados. As sínteses ajudam a desenvolver uma análise auto-organizada de qualidade e com clareza. Nessa etapa do estudo, as sínteses aglutinam as ideias enunciadas nas unidades de significados que deram origem à categoria à qual pertencem.

A partir das 14 categorias intermediárias, retomamos o processo de comparação e aglutinação, em um movimento interpretativo, assim chegando à construção de três categorias finais, expressas no Quadro 4.

Quadro 4: Codificação e expressões das categorias finais

\begin{tabular}{|c|c|c|}
\hline $\begin{array}{l}\text { Código das } \\
\text { categorias iniciais }\end{array}$ & Categoria final & $\begin{array}{l}\text { Código da } \\
\text { categoria final }\end{array}$ \\
\hline $8,13,16,19,20$ & $\begin{array}{c}\text { Investigação do professor com registros da } \\
\text { experiência }\end{array}$ & A \\
\hline $\begin{array}{l}2,9,10,11,12,15 \\
22,24,31\end{array}$ & $\begin{array}{l}\text { Formação de professores no coletivo da escola e da } \\
\text { universidade }\end{array}$ & B \\
\hline
\end{tabular}




\begin{tabular}{|c|c|c|}
\hline $1,5,14,17,18,23$ & $\begin{array}{c}\text { Aperfeiçoamento de saberes do professor ao } \\
\text { planejar, com diálogo, ações investigativas }\end{array}$ & C \\
\hline $3,6,21,26,27,28,29$ & Investigação dialógica na sala de aula de Ciências & $\mathrm{D}$ \\
\hline
\end{tabular}

Fonte: Guidotti (2019, p. 164)

Significamos que as categorias finais são resultantes de um intenso movimento de imersão dos pesquisadores no corpus de análise. Nesse processo, deixamos os fenômenos manifestarem-se, construindo categorias a partir das inúmeras informações emergentes do campo empírico. Como podemos observar nos Quadros 2, 3 e 4, partimos de 250 unidades de sentido, que representam categorias bem específicas e restritas, categorias essas que são cada vez mais amplas e em menor número. Na próxima seção, abordamos o movimento de sistematização dos argumentos que comunicam as compreensões.

\section{Considerações finais: argumentos que comunicam compreensões}

O movimento da busca por compreender na etnopesquisa, em uma pespectiva fenomenológica hermenêutica, desenrolou-se de modo espiralado, não linear, em círculos que progrediram sem retornar ao ponto de partida - um objeto aperfeiçoável. Inicialmente, descrevemos para compreender o campo investigado, procurando perceber o fenômeno em sua totalidade. A partir disso, delineamos o caminho, com o objetivo de situar o fenômeno, que já se apresentava de forma velada. Por fim, auxiliados pelos pressupostos da ATD, mergulhamos nos aspectos essenciais do fenômeno - investigação sobre a/na sala de aula de Ciências.

Esse modo de fazer pesquisa diferencia-se das pesquisas de princípio positivista, em que o pesquisador deve estar distante do pesquisado para construir conhecimento; na etnopesquisa-formação, o pesquisador deve estar ou tornar-se membro da comunidade investigada. Apoiados nesse ponto, justificamos o uso do termo etnopesquisa-formação, por significarmos e percebermos que, ao avançarem na investigação, os próprios pesquisadores estavam em transformação, a partir de um coletivo, em termos teóricos, epistemológicos, metodológicos e profissionais. Nesse sentido, concordamos com Macedo (2010), pois não há negação dos pesquisadores em relação à sua subjetividade, tirando-se partido dessa condição ontológica.

Entretanto, todo esse movimento ainda não trata da possibilidade de comunicar um argumento final. Essa não deve ser a pretensão do pesquisador fenomenológico, uma vez que, ao assumirmos que o compreender acontece de forma espiralada, os argumentos construídos ao longo da etnopesquisa, delimitados por um tempo cronológico-acadêmico, 
podem ser aperfeiçoados a partir de novas experiências. No entanto, como temos de nos aproximar do ponto final em algum lugar, o desafio foi produzir metatextos teorizados e articulados com as informações do campo empírico, abrangendo descrição, interpretação e argumentação integradora.

No estudo em análise, produzimos dois metatextos, cada um constituído por quatro categorias que auxiliaram na sistematização de argumentos, como forma de comunicar o que se compreendeu. No metatexto, o descrever significa expressar, de modo organizado, sentidos e significados percebidos próximos do campo empírico. No entanto, a descrição não é suficiente, exigindo dos pesquisadores um afastamento desses enunciados, para atingirem interpretações mais aprofundadas (MORAES; GALIAZZI, 2016). Isso significa comunicar novas relações e inferências entre aspectos constituintes do fenômeno situado durante a análise, complexificados com a teoria e com conhecimentos tácitos dos pesquisadores.

Nesse movimento de interpretação, as informações do campo empírico, as experiências de quem pesquisa e as teorias articulam-se, constituindo uma rede de significados que expressam compreensões construídas pelos pesquisadores em relação ao fenômeno estudado. Assumimos essas expressões como argumentos derivados das categorias de análise, conectando as diferentes dimensões que abrangem a constituição dos novos conhecimentos e dando-lhes sentido.

No Quadro 5, apresentamos o conjunto de argumentos emergentes da produção textual das quatro categorias finais. $\mathrm{O}$ argumento aglutinador expressa relações entre os argumentos das categorias finais, com foco no comunicar o que se compreendeu a partir da pergunta em análise. 
Quadro 5: A comunicação do compreender via argumentos emergentes na ATD

O QUE É ISSO DA INVESTIGAÇÃO DOS PROFESSORES SOBRE A/NA SALA DE AULA DE CIÊNCIAS?

\section{PRIMEIRO ARGUMENTO DA TESE}

A investigação mostra-se como um processo reflexivo de autoformação e transformação de professores no CIRANDAR constituído pelo questionamento das práticas de sala de aula, a partir da apropriação de teorias, de experiências rememoradas, registros escritos, diálogos e análises.

\section{SEGUNDO ARGUMENTO DA TESE}

A formação de professores acontece com o aperfeiçoamento teórico-prático de ser professor, em interações colaborativas entre licenciandos, professor da escola e da universidade.

\section{TERCEIRO ARGUMENTO DA TESE}

Ações investigativas mostram-se como estratégia didático-pedagógica em Ciências e desafiam o planejamento com diálogo, com escuta e colaboração entre os professores, futuros professores e seus estudantes.

\section{QUARTO ARGUMENTO DA TESE}

A investigação dialógica mostra-se como estratégia didático-pedagógica, desencadeada pela problematização, com questionamentos dos estudantes e professores, ao operar, de forma coletiva, as informações e a linguagem científica no constituir, negociar e produzir significados na sala de aula de Ciências.

\section{ARGUMENTO AGLUTINADOR - TESE}

A investigação mostra-se nas escritas do CIRANDAR como um processo dialógico de autoformação com professores e como aperfeiçoamento didático-pedagógico da sala de aula de Ciências.

Fonte: Guidotti (2019, p. 217)

O Quadro 5 expõe a construção do argumento aglutinador como resultado de um movimento de interconexão das diferentes categorias finais, que estabelecem condições para a estruturação da compreensão do todo. Além disso, expõe a interrogação, aperfeiçoada de acordo com a temporalidade vivida durante o processo de investigação. Em outras palavras, o argumento aglutinador, ou tese, é um produto do avanço da compreensão dos pesquisadores que responde a interrogação que os movimentou na investigação.

Consideramos que esse é um modo de comunicar o compreender com a ATD, com a interligação dos distintos argumentos emergentes nos metatextos, em uma etnopesquisa-formação com professores de Ciências. O movimento envolveu a reconstrução do corpus de análise, reorganizando as subcategorias em interconexão com as unidades de significados construídas e com as diferentes unidades constituídas diante da ampliação da Análise Textual Discursiva. A escrita em forma de textos transformounos enquanto pesquisadores e na forma que assumimos no comunicar o que se 
compreendeu no estudo. Outros caminhos e modos de comunicar compreensões serão constituídos com a ATD, pois não a assumimos como única forma de fazê-lo.

\section{Referências}

BARBOSA, S. M. C; BARBOSA, J. G. Etnometodologia multirreferencial: contribuições teórico epistemológicas para a formação do professor-pesquisador. Educação \& Linguagem, [S. I]. v. 11, n. 18, p. 238-256. 2008.

BICUDO, M. A. Pesquisa qualitativa segundo a visão fenomenológica. São Paulo: Cortez. 2011.

BICUDO, M. A. Pesquisa Fenomenológica em Educação: Possibilidades e desafios. Revista Paradigma, Ribeirão Preto, v. XLI, p. 30-56, jun. 2020.

COULON, A. Etnometodologia e Educação. São Paulo: Cortez. 2017.

GADAMER, Hans-Georg. Verdade e Método: Traços Fundamentais de uma Hermenêutica Filosófica. 3. ed. Editora Vozes, Petrópolis, 1999.

GUIDOTTI, C. A investigação desde a sala de aula de ciências: processo de autoformação com aperfeiçoamento teórico-prático de professores no cirandar. 2019. Tese (Doutorado em Educação em Ciências) - Instituto de Matemática, Estátistica e Física, Universidade Federal do Rio Grande, Rio Grande, 2019.

MACEDO, R. S. Etnopesquisa crítica: Etnopesquisa formação. 2. ed. Brasília: Liber Ars. 2010.

MARQUES, M. O. Escrever é preciso: o princípio da pesquisa. 5.ed. Ijuí: Unijuí. 2011.

MORAES, R.; GALIAZZI, M. C. Análise textual discursiva. 3 ed. Ijuí: Unijuí, 2016.

MORAES, R. Percursos de formação de professores de Ciências: histórias de formação e profissionalização. Curitiba: Appris editora, 2019.

SOUSA, R. S.; GALIAZZI, M. do C. Compreensões acerca da hermenêutica na análise textual discursiva: marcas teórico-metodológicas à investigação. Revista Contexto \& Educação, [S. I.], v. 31, n. 100, p. 33-55. 2017.

WELLS, G. Integração da teoria histórico-cultural da atividade com a pesquisa-ação. In: GALIAZZI, M. C. et al. Indagações dialógicas com Gordon Wells. Rio Grande: FURG, 2016. p. $07-44$.

Recebido em: 29 de outubro de 2020.

Aceito em: 21 de novembro de 2020. 